\title{
LA PERCEPCIÓN DE LA CATÁSTROFE: SEQUÍA E INUNDACIONES EN TIERRAS VALENCIANAS DURANTE LA PRIMERA MITAD DEL SIGLO XVIII*
}

\section{Armando ALBEROLA ROMÁ}

Universidad de Alicante

En la actualidad conocemos de un modo relativamente fiable cual ha sido la realidad climática en los diferentes períodos históricos merced a las investigaciones llevadas a cabo por algunos estudiosos preocupados por estas cuestiones ${ }^{2}$. El interés por las mismas no resulta ocioso, pues está fuera de duda que las variaciones climáticas han influido poderosamente en el devenir de los pueblos $\mathrm{y}$, en ocasiones, han llegado a desempeñar un papel determinante en acontecimientos históricos de cierta trascendencia. Hace ya bastantes años Domínguez Ortiz llamaba la atención acerca del enorme interés que podía tener para los historiadores el estudio de las oscilaciones climáticas a la hora de hallar explicaciones a la coyuntura agrícola. Aludía a lo escasos que andábamos de este tipo de análisis en nuestro pais, mostrándose esperanzado ante los resultados que podría arrojar la exhaustiva encuesta que, por entonces, llevaba a cabo Fontana Tarrats ${ }^{2}$. La reciente sintesis de historia climática elaborada por Font Tullot relativa a nuestro país nos permite disponer de una serie de referencias de indudable interés y, no cabe duda de que, en la medida en que proliferen los análisis de tipo regional, mejorará la fiabilidad de sus apreciaciones.

En el siglo XVIII se produjo el paso a unas condiciones climáticas más cálidas, aunque el invierno de 1708-1709 fue especialmente duro, al igual que el de $1716^{3}$. No obstante, a partir de 17:8 los fuertes calores estivales marcan el comienzo de una fase cálida que, salpicada de inviernos de cierta crudeza, se mantendrá hasta la década de los sesenta. En el ámbito peninsular parece anunciarse, en estos años, la transición hacia una fase algo más fría o, cuando menos, sacudida por violentas oscilaciones meteorológicas. 
Las sequias de tipo general y larga duración no fueron frecuentes excepción hecha el periodo 1749-1753, un auténtico acontecimiento parangonable a la esterilidad padecida durante los años 1981-1984. Más habituales e insistentes resultaron las sequías de tipo local, de las que las sufridas en Alicante serían un claro ejemplo, que hallarian su adecuado encuadre en las características propias de las diferentes regiones climáticas peninsulares. Si hubiera que destacar algún hito especialmente significativo, cabría referirse, en primer lugar, a la sequia que desde el otoño de 1718 -coincidiendo con el inicio de la fase cálida- afectó durante siete cosechas a las comarcas agrícolas próximas a la zona de los Monegros.

En las tierras valencianas fueron años difíciles 1720-1724, 1725, 1757, los comienzos de la década de los sesenta, 1772-1774, 1779 y 1792 . El problema en este ámbito se complicaba aún más ya que, de manera esporádica, se solían producir precipitaciones torrenciales de alta intensidad horaria con su corolario de fuertes avenidas e inundaciones apreciables, sobre todo, a partir de la segunda mitad del siglo. La frecuencia de este tipo de fenómenos atmosféricos, a los que acompañaban en ocasiones plagas y epidemias, condicionaba sobremanera los años agrícolas y alteraba la normalidad de las economías campesinas ${ }^{4}$.

\section{Las dificultades de comienzos de siglo}

Aparte de los inconvenientes de signo climático habituales en las tierras valencianas hay que aludir, en los albores de la centuria, a una cuestion que afectó sobremanera al desarrollo económico, político e institucional de los habitantes del antiguo reino de Valencia. Me refiero a la Guerra de Sucesión. El conflicto bélico dejó su amarga impronta en este territorio, sobre todo tras la derrota austracista en la batalla de Almansa acaecida a finales de abril del año 1707.

El severo invierno de 1708-1709 se tradujo en una pésima cosecha que propició la primera gran crisis europea de la centuria -"crisis universal" es denominada-, aunque su tipologia parece responder todavía a las crisis de subsistencia propias del siglo XVII . Esta crisis de 1709 se alargó prácticamente hasta la de $1712-$ 1713 , en la que una acentuación de la presión fiscal contribuiria a incrementar las dificultades de la población valenciana. La década de los veinte estuvo marcada por el inicio de un período climático cálido ya anunciado por el fuerte verano de 1718 . Los calores se prolongaron durante el otoño, inaugurándose en algunas áreas peninsulares, como es el caso de los Monegros, una fase de casi ocho años sin cosechas. El recurso al trigo marítimo o de importación para abastecer a las poblaciones del reino valenciano se vio seriamente condicionado por la peste de Marsella del año 1720, al arbitrarse medidas tendentes a la salvaguarda de la salud pública, pero que limitaban sobremanera el tránsito de buques y mercancías. 
Una pesquisa llevada a cabo por la Intendencia valenciana entre labradores y comerciantes de grano puso de manifiesto la escasez de las cosechas de grano para el año 1722 como consecuencia de la sequia ${ }^{6}$. Tres años más tarde ésta cra extrema, tal y como confirman diferentes fuentes documentales. Así, en el mes de mayo el gobierno municipal de la ciudad de Alcoi daba la señal de alarma ante la certeza de una corta cosecha. Su preocupación fue en aumento tras comprobar el escaso trigo que quedaba, no encontrando más solución que el inicio de rogativas en demanda de lluvias portando en procesión las imágenes de Nuestra Señora de Gracia y del Niño Jesús del Milagro. El escaso éxito de estas plegarias hizo que persistieran las rogativas durante todo el verano. A mediados de septiembre la situación no había cambiado en absoluto, por lo que el cabildo ciudadano acordó perseverar en su actitud $^{7}$. Ya a primeros de noviembre se dispuso una procesión general en la que, además de las imágenes anteriormente portadas, se llevaron a la iglesia parroquial de la villa las de San Jorge, San Agustin y San Francisco para que alli les fueran hechas todos los días las rogativas de rigor. Las lluvias caídas durante los días 15 y 16 de diciembre de ese año 1725 fueron saludadas con alborozo por los munícipes alcoyanos en su reunión del día 17 de ese mes, programándose para la mañana del domingo inmediato una misa cantada y un solemne Te Deum. Por la tarde, y completando la acción de gracias, se llevaría a cabo una procesión.

En Orihuela, en el sur del País Valenciano, hay constancia de la celebración de rogativas ad petendam pluviam en febrero de $1726^{8}$. Idénticas acciones tuvieron lugar, por las mismas fechas, en Segorbe; lo que podria dar una idea del carácter generalizado y pertinaz de esta sequia?.

La ciudad de Alicante, por su parte, había venido celebrando rogativas durante toda la década de los veinte debido a la acusada falta de precipitaciones. El recurso a la reliquia de la Santa Faz, custodiada por monjas clarisas en el monasterio de idéntico nombre ${ }^{10}$, era considerado como la única solución con visos de exito para que la situación meteorológica cambiara. Ya durante el año 1725 , y a la vista de que persistía la esterilidad de los campos, se acordó por el cabildo municipal el día ocho de enero que las rogativas -que hasta ese momento habian sido secretas- se transformaran en públicas. Para ello se decidió pasar el correspondiente recado a los cabildos eclesiásticos de las iglesias de San Nicolás y de Santa María, asi como a las comunidades religiosas asentadas en la localidad. Acabadas las rogativas, como la lluvia caída había resultado insignificante, se acordó una nueva función religiosa, esta vez en el propio monasterio de la Santa Faz ${ }^{11}$.

La persistencia de la sequía durante este año acrecentó las dificultades de 1726. A fines de enero los regidores alicantinos ponían de relieve que, pese a haberse llevado a cabo en todas las iglesias rogativas públicas ante la falta de agua, "continúa esta calamidad". Por ello propugnaban demandar la protección de la Santa Faz, celebrando en su monasterio una misa y una procesión precedida de niños en la que implorar la "divina misericordia"12. 
Si la sequía solía ser la principal causa de pérdida de las cosechas, ello no quiere indicar que fuera la única. Heladas, pedrisco o un exceso de lluvias con la consiguiente riada o inundación podían dar al traste con las producciones agricolas del año en cuestión e, incluso, condicionar las de los siguientes en función del grado de deterioro del suelo. Hay constancia de notables aguaceros en el Levante peninsular a finales de la década de los veinte, destacando por su intensidad el que descargó sobre Utiel el 24 de abril de $1728^{13}$.

Orihuela, pese a la continua sequía que padeció durante esa década, no escapó a las inundaciones del río Segura que, de manera sistemática e irremediable, se presentaban en la estación otoñal ${ }^{14}$. En el año 1723 , tras largos meses de sequedad, hambre y fiebres, la lluvia se presentó en el mes de julio después de innumerables rogativas que la habian demandado. El río se desbordó por dos veces en la primera quincena de octubre; situación que se reprodujo al año siguiente en el mismo mes. Los años 1726 y 1727 conocieron nuevas inundaciones que no llegaron a alcanzar a la totalidad de la vega oriolana, aunque motivaron la realización de rogativas encaminadas a aplacar los temporales de lluvia ${ }^{15}$. Mayor importancia parece ser que alcanzó la crecida que tuvo lugar a finales del mes de octubre de 1728, y a cuyos efectos se unieron los causados por un terremoto que se dejó sentir en la propia Orihuela, Murcia, Rojales, Dolores, Guardamar y el Cabo Cervera.

\section{La década de los treinta, tiempo de avenidas e inundaciones}

La ciudad de Valencia conoció una tremenda inundación a partir de las tres de la tarde del día 16 de septiembre de $1731^{16}$. El río Turia marchaba tan cargado de agua que llegó a cubrir los pretiles de los puentes. El dietarista Padre Teixidó, al que sigue puntualmente Boix y Ricarte, describe con gran lujo de detalles el alcance del desastre, acrecentado por el gran número de maderos que circulaban río abajo y que a punto estuvieron de destruir el puente del Real. La ciudad quedó prácticamente anegada, siendo precisa la utilización de barcas para prestar los socorros oportunos. Los conventos de Santa Mónica y de la Zaidía fueron invadidos por las aguas; la calle Murviedro quedó por debajo del nivel de aquéllas lo que provocó la muerte de más de doscientos carneros atrapados en su corral y la pérdida de más de mil arrobas de aceite de un artesano jabonero. Incluso las caballerizas del palacio Real quedaron inundadas, aunque donde más afluyó el agua fue en el llano de Quart, causando grandes estragos en Aldaia, el barranco de Torrent y en Alaquás, donde sólo restaron en pie once casas. La ruína se instaló en la ciudad y su término, decretándose por el Capitán General el rezo de rogativas en un altar instalado en un balcón del propio palacio, donde fue expuesto el Santísimo.

En el lugar de Torrent esta gran inundación arrasó las tierras de labor y destruyó la práctica totalidad del arbolado y las vides, su principal riqueza. Los daños, según tasación judicial, ascendieron a 21.841 libras al haberse perdido 
integramente la cosecha de vino de ese año y no poderse "sembrar los granos en las tierras dispuestas por haver quedado desustanciadas"17.

Este desastre suponía, al decir de los vecinos, que no podrian hacer frente al pago del equivalente que les correspondía en el año 1732 -estimado en 5.400 libras- ni, por supuesto, al de los réditos anuales de los censos con que estaba cargado el lugar, cuyo capital principal superaba las 19.700 libras. Por ello recurrieron a Felipe $\mathrm{V}$ con el fin de que les dispensara de sus tributos durante seis años, aparte de lo que adeudaran por el que estaba en curso, con el fin de que tuvieran la oportunidad de recuperarse de la desgracia "y volver a contribuir con mas aliento en quanto sea del servicio de V.Mgd.". El monarca, como solía ser habitual cuando se producía este tipo de situaciones, recabó a finales del año 1732 del Intendente valenciano información precisa acerca de la veracidad del memorial elevado por Torrent. Su respuesta confirmó la inundación y los daños, que extendía además a lugares próximos al casco urbano del lugar. Pese a todo, el Intendente únicamente había considerado la rebaja en 100 libras de la cuota del equivalente del año 1732 aunque, a tenor de los elevados censos que soportaba la localidad, se permitía sugerir al rey una rebaja de la tercera parte del equivalente durante cuatro o seis años. Aunque no tenemos constancia documental, es muy probable que el monarca aceptara la sugerencia del Intendente puesto que ello solía ser la pauta habitual de comportamiento en estos casos.

En la primavera de 1736 , y contra lo que solía ser habitual, tuvo lugar otra crecida del río Turia. El nueve de abril, festividad de San Vicente Ferrer, comenzó a llover intensamente y no paró por espacio de diez días. Ello provocó el desbordamiento del río el quince de ese mes aunque, a diferencia de cinco años atrás, no hubo que lamentar pérdidas excepción hecha en la zona de Monte Olivete ${ }^{18}$.

En contraste con esta situación, en Alicante y Orihuela continuaba instalada la pertinaz sequia. Las actas del cabildo alicantino ponen de manifiesto la esterilidad que ofrecían los campos ante la reiterada ausencia de lluvias. Los años 1730, 1737 y 1739 recogen resoluciones para llevar a cabo rogativas, trayendo a la iglesia colegial de la ciudad la reliquia de la Santa Faz al objeto de conjurar la aridez imperante ${ }^{19}$. Aunque se vivía en un estado de permanente sequía por estos años, ello no excluía la posibilidad de fuertes chubascos en los meses equinocciales, de efectos desastrosos en la mayoria de las ocasiones tanto para los campos como para los inmuebles urbanos. Así, los efectos de un gran temporal que se abatió sobre la ciudad de Orihuela motivó, a primeros de junio de 1731, la celebración de rogativas a la Virgen de Monserrate ${ }^{20}$. El río Segura se desbordó a mediados del mes de septiembre originando una tremenda riada, conocida como de San Nicomedes, que ocasionó numerosas víctimas y acabó con todas las cosechas.

Sin embargo la mayor crecida del rio tuvo lugar en el año 1732. Ocurrió en el mes de septiembre, alcanzando el agua una altura de más de catorce palmos sobre 
las tierras de la huerta a la vez que inundaba toda la ciudad. Aparte de las cosechas, se perdieron todos los animales de granja y labor, así como las personas que no pudieron subirse a los árboles ${ }^{21}$. Las procesiones portando la imagen de la virgen de Monserrate para demandar la templanza de las fuerzas de la naturaleza no se hicieron esperar, desarrollándose con toda solemnidad los días 6 y 9 de septiembre ${ }^{22}$.

Las copiosas lluvias primaverales del año 1736 hicieron que el cabildo municipal, temeroso de lo que pudiera ocurrir, convocara a los vecinos de Orihuela a una solemne procesión, en la que se arrojó un ramo de flores al rio intentando evitar lo peor. Vano intento: entre los días 20 y 25 de abril el Segura creció de modo espectacular, convirtiendo en un amplio mar los dominios de la ciudad y su huerta. En ésta las aguas alcanzaron tal altura que llegaron a cubrir a los árboles y destruyeron todas las barracas, mientras que en la ciudad no quedó edificio en el que no penetrara el agua. En el mes de septiembre todavía hubo una nueva inundación, que motivó la consiguiente procesión con lanzamiento de flores al río el día 26. Hasta el final de la década la sequía se erigió en protagonista en las tierras meridionales valencianas -aunque con esporádicos desbordamientos del río Segura-, motivando en Orihuela y Alicante la continua celebración de rogativas y procesiones impetrando lluvias ${ }^{23}$.

\section{Los acusados contrastes de la década central del siglo}

El sur del antiguo reino valenciano conoció, a finales de octubre del año 1751 , importantes inundaciones que afectaron seriamente a las poblaciones ubicadas en el Bajo Segura, fundamentalmente a Orihuela. El contraste con la sequía padecida en el año anterior, que motivó la práctica de rogativas por los campos encabezadas por la imagen de la Virgen de Monserrate ${ }^{24}$, es una muestra más de los vaivenes meteorológicos propios de estas tierras en primavera y otoño.

En ese sentido resulta revelador el detallado informe elaborado por el regidor oriolano Ruiz de Villafranca ${ }^{25}$. Por él sabemos que el temporal se alargó por espacio de dieciocho días y que, al descargar el agua tanto en el término de Orihuela como, sobre todo, en el curso superior del rio Segura se produjeron impetuosas avenidas que anegaron la vega y ocasionaron daños en la agricultura y ganaderia locales valorados en cerca de 880.000 libras, difícilmente reparables a corto plazo ${ }^{26}$.

Ante esta situación la ciudad acordó solicitar a primeros de noviembre de 1751 una rebaja en la porción del equivalente que le correspondía en esa anualidad. Para ello el cabildo ciudadano recurrió al marqués de la Ensenada así como a los buenos oficios que pudiera desplegar el propio obispo de Orihuela ante el monarca, para que considerara favorablemente la petición. Como última acción tuvo lugar, el día quince de ese mismo mes de noviembre, una rogativa portando la Virgen de Monserrate para que aplacara la furia de los elementos ${ }^{27}$. 
En Alicante, por contra, la sequía continuaba instalada acrecentándose las dificultades de su huerta ante el desvio que de las aguas del río Montenegre efectuaban los vecinos de su curso alto ${ }^{28}$. Ni se podía dar riego a los sembrados ni los diferentes molinos que jalonaban las riberas del Montenegre podían llevar a cabo las moliendas. El cabildo ciudadano acordó el 21 de mayo tomar medidas para que los vecinos de Castalla, Tibi y Jijona demolieran las presas que, ilegalmente, habian alzado en el cauce del río. A la vez, solicitaban del cabildo y clero de la iglesia colegial de San Nicolás el inicio de rogativas públicas en demanda de las necesarias lluvias ${ }^{29}$.

Esta década de los cincuenta fue pródiga en contrastes. Así, a título de mera anécdota, la ciudad de Alicante contempló una copiosa e inusual nevada en $1752^{30}$ tras haber soportado acusadas sequías en el bienio 1747-1748 que hicieron rendir menguadas cosechas a los campos ${ }^{31}$. Sin embargo en 1756 el antiguo reino valenciano padeció fortísimos aguaceros que provocaron inundaciones que pusieron en grave riesgo las comunicaciones terrestres impidiendo la llegada de grano a la capital, desencadenaron el alza de los precios del pan y pusieron en graves aprietos a las autoridades municipales. La crisis, cuyos efectos pretendían neutralizar los responsables valencianos, había sido consecuencia de un cúmulo de factores de entre los que el climático tenía su importancia, aunque no fuera el único. Así, a las torrenciales lluvias que colapsaron las precarias comunicaciones de la época, se sumaron los daños ocasionados por la plaga de langosta que azotó el Levante español entre 1756 y 1757 , junto con los efectos negativos que, para el tráfico de grano ultramarino, tuvo la guerra de los Siete Años ${ }^{32}$.

En el verano de 1757 fuertes tempestades, acompañadas de pedrisco, afectaron al lugar de Soneja y a la baronía de Azuébar, ambas en el Alto Palancia. El memorial remitido por los regidores de ambas poblaciones especificaba que los dias veinte de julio y ocho de agosto habían sufrido

"tan recia tempestad que se apedreó todo aquel termino (...) de manera que han dejado sin ojas los arboles, los frutos de granos perdidos, la uva y los otros frutos pendientes enteramente cortados $y$ echados por tierra, siendo tal el daño que causó que ni el cuidado de labradores (...) podrá restablecerlo en muchos años" ${ }^{\prime \prime 3}$.

Ante la caótica situación, y como solía ser habitual, Soneja y Azuébar solicitaban el perdón durante un año de sus respectivos equivalentes, estimados en 538 y 109 libras. Don Pedro Rebollar, intendente de Valencia, tras comprobar la veracidad de lo contenido en el memorial consideraba que era de justicia acceder a la petición, aunque proponía al monarca que la rebaja solicitada en el equivalente se llevara a efecto la mitad en el año en curso y la otra mitad en el siguiente ${ }^{34}$. A primeros de diciembre de ese año 1757, Fernando VI daba su aprobación a lo 
propuesto por el intendente $y$, en consecuencia, perdonaba durante un año el equivalente de las poblaciones indicadas.

En la vecina comarca del Alto Mijares encontramos más pruebas de lo poco propicios que resultaron los primeros años de la segunda mitad del siglo XVIII. No hay más que detenerse en la lectura de los informes, con sus correspondientes peticiones, remitidos a la corte a finales de octubre de 1756 y de septiembre de 1757 , respectivamente, por los lugares de Argelita y del Castillo de Villamalefa.

Argelita, lugar de corto vecindario y escaso término municipal próximo al río Mijares, solicitaba probablemente a finales de 1755 o principios de 1756 una minoración de la deuda de 237 libras que arrastraba por no haber satisfecho en su momento el equivalente que le correspondía. El memorial, firmado por los integrantes del gobierno municipal, argumentaba que una fuerte tempestad descargó en el mes de junio del año 1755 sobre el lugar. Como consecuencia de ella el río Mijares se desbordó y arruinó gran parte del término, quedando improductivas las tierras por "la muchedumbre de peñas que en ellas introdujeron el río y barranco que las inundaron ${ }^{\prime 3}$.

Argelita planteó cuidadosamente su reclamación, adjuntando un detallado justiprecio de los bienes que poseía como municipio así como las cargas físcales que soportaba. Del mismo se desprende que los recursos del lugar, una vez tasadas las tierras y los inmuebles, alcanzaban una valoración de 24.202 libras. En pagar intereses y capitales de los censos detraía cada año 2.174 libras, a las que había que añadir otras 375 en concepto de equivalente y otras contribuciones. Todo ello asumido por sus 52 vecinos y los 37 terratenientes que disponían de propiedades agrarias en el término municipal. Ante los estragos causados por la tormenta y riada mencionadas, evaluados en 7.620 libras, la localidad se declaraba incapaz de asumir sus compromisos con la real hacienda, por lo que solicitaba la condonación del pago del equivalente de ese año ${ }^{36}$. El informe de don Pedro Rebollar de la Concha, a la sazón en la corte por asuntos de su cargo de intendente, reconocía la veracidad de lo manifestado $y$, atendiendo a que era la segunda vez que Argelita solicitaba tal gracia, propuso que se le dispensara el pago de las dos terceras partes del equivalente, cosa que fue aceptada por el monarca ${ }^{37}$.

Año especialmente negativo fue 1757 , en el que a las intensas precipitaciones que entorpecieron durante el otoño el tránsito por los caminos del antiguo reino cabe añadir los dolorosos efectos causados por la persistencia de la plaga de langosta iniciada un año atrás. En 1758 la sequia dejó sentir de nuevo sus efectos en las tierras meridionales del reino. En Orihuela se hacían frecuentes las rogativas y procesiones en los meses de febrero y noviembre ${ }^{38}$, mientras que en Aspe la situación alcanzaba altas cotas de pesimismo por cuanto a los estragos causados por la plaga de langosta de los años 1756 y 1757 se añadían los derivados de una pertinaz sequía en 1758 que 
"ha dexado aridos y secos totalmente los sembrados, de manera que no se espera cosecha alguna de granos, siendo como es el unico remedio para la subsistencia de este pueblo"39.

La ausencia de lluvias en 1758 hacía previsible un mal año agrícola, lo cual garantizaba la aparición de la miseria en la localidad ${ }^{40}$. La información fue remitida el 25 de abril de 1758 al corregidor de Orihuela quien, a su vez, la elevó a la Intendencia del reino. En este caso no tenemos constancia de cual fue la resolución adoptada.

La ciudad de Alicante, ante la persistente sequía, acordó a finales de noviembre de 1759 detraer 10 libras del fondo de la denominada bolsa del vino con el fin de poder financiar los gastos que suponía la celebración de una solemne misa de rogativa en el monasterio de la Sant $\mathrm{Faz}^{41}$. En claro contraste con esta situación padecida en el mediodía valenciano, la población de Fuente la Reina, situada en la comarca más septentrional del Alto Mijares, reclamaba la dispensa del equivalente del año 1758 al haber visto como sus cultivos eran arrasados por fuertes tormentas y avenidas. Ante lo limitado de los recursos del lugar, de lo que da buena prueba el hecho de que tan sólo pagara 146 libras por el equivalente, el marqués de Avilés era partidario de que se le perdonara la mitad de esa contribución en atención a que, con reiterada frecuencia, sufría estragos del tipo de los ya indicados ${ }^{42}$.

La década central del siglo arroja un balance poco favorable para un buen número de comarcas valencianas y si hubiera que emplear alguna palabra para calificarla en su conjunto ésta sería, sin duda, "contraste". Y ello porque, pese a la persistencia de la sequía -apreciable sobre todo en las tierras meridionales-, las fuertes tempestades y granizos veraniegos malograron buen número de cosechas. A ello cabría añadir las intensas precipitaciones, generalizadas en todo el antiguo reino valenciano, del año 1756 que provocaron notables inundaciones y, como guinda final, los efectos devastadores que la plaga de langosta dejó sentir en los años 1756 a 1758. 


\section{NOTAS}

*.- El presente trabajo ha sido realizado en el marco de un Proyecto de Investigación que conto, para su desarrollo, con una Beca del Subprograma de Estancias Temporales en España y en el Extranjero concedido en 1993 por la Conselleria d'Educació i Ciència (Direcció Gencral d'Ensenyaments Universitaris) de la Generalitat Valenciana.

1.- No está de mas recordar los trabajos de, entre otros, H.H. Lamb: Climate history and the Modern World. Methuen and Co. Ltd. Londres, 1982. E. Le Roy Ladurie: Histoire du chimat depuis l'an mil. Flammarion. París, 1983: hay edición en castellano titulada Historia del clima desde el año mii. Fondo de Cultura Economica. México. 1991. Este mismo autor tiene interesantes reflexiones acerca de estas cuestiones de climatologia histórica en Le territoire de I'historien. Paris, 1973. A. Bryson Reid y Th. T. Murray: El clima y la historia. Mexico, 1985. P. Alexandre: Le climar en Europe au Moyen Age. Contribution á l'histoire des variations climatiques de 1.000 à 1.425 d'aprés les sources narratrves de l'Europe Occidentale. Paris, 1987. Para el caso español ver I. Font Tullot: Historia del clima en España. Cambios climáticos y sus causas. Instituto Nacional de Meteorología. Madrid, 1988. J.A. Álvarez Vázquez: Sequias y lliwias en la provincia de Zamora en los siglos XVII. XVIII y XIX. Universidad Autonoma. Madrid, 1986. J. Díaz-Pintado: "Climatología de La Mancha durante el siglo XVIII", en Cuadernos de Historia Moderna, $\mathrm{n}^{\circ} 12$ (Madrid. 1991), pp. 123-166.

2.- A. Dominguez. Ortiz: Sociedad y Estado en el siglo XVIII español. Barcelona, 1976, pp. 404-405.

3.- II. Kamen: La Guerra de Sucesión en España, 1700-17/5. Barcelona, 1974, pp. 391-392, 402. 424. Los datos generales que anoto a continuación proceden, en su mayor parte, de I. Font Tullot: Historia del clima de España, pp. 99-107.

4.- A. Alberola Roma: "De catástrofes climáticas y piagas. Una aproximación a las crisis agrarias valencianas de la segunda mitad del siglo XVIIl", en J. Pérez y A. Alberola (Eds.): España y América entre la llustración y el liberalismo, Casa de Velázquez-Instituto de Cultura "Juan Gil-Albert", MadridAlicante, 1993, pp. 109-130.

5.- El invierno de 1708-1709 fue histórico por su rigurosidad e inclemencia. Existen datos que avalan esta alirmación: el mar Báltico permaneció helado durante buena parte de la estación. en Inglaterra fueron muy abundantes las nevadas, en Francia quedaron destruídos muchos cultivos arboreos como consecuencia de la extrema sequedad y fuertes heladas, en España se heló el río Ebro a su paso por Tortosa mientras que en Sevilla quedó registrado como un invierno de los que "jamás se habian conocido". Cifr. en I. Font Tullot: Historia del clima en España, pp. 95 y 99. El marqués de San Felipe, al referirse al invierno de $17(09$, indicaba rotundo: "no se recuerda que haya habido nunca un invierno tan helado como este". La situación aủn se complicó más en la primavera, pues las excesivas lluvias incrementaron los efectos negativos del deshielo y tornaron intransitables los caminos; cifr. en V. Bacallar de Sanna, marques de San Felipe: Comentarios de la guerra de España e historia de su rey Felipe $V$, el animoso. B.A.E. Madrid, 1957, pág. 167. A nivel más local referir que los defensores ingleses del castillo de Alicante, último reducto austracista en tierras valencianas hasta la primavera de 1709 , hicieron frecuentes salidas durante el invierno para conseguir leña con la que encender fuego para minorar el frío y alimentar las cocinas; cifr. en J.B. Maltés y L. López: Ilice Ilustrada. Historia de la mury noble, leal y fidelisima ciudad de Alicante. Década VII, epígrafes 141, 156 y 157. Copia manuscrita de 1889 del original de 1752 . Hay una reciente edición facsímil de esta copia, con un estudio preliminar de A. Alberola y C. Mas, publicada por el Ayuntamiento de Alicante en 1991 dentro de su colección Fuentes Historicas de Alicante. 
6.- Archivo del Reino de Valencia (ARV). Bailia-Intendencia, n" 3048, cifr. en J.M. Palop Ramos: Hambre y lucha antifendal. Las crisis de subsistencias en Valencia (siglo XVIII), Madrid, 1977, pp. 79-80, nota 11.

7.- J. Berenguer Barceló: Historia de Alcoy: Recopilación de documentos, testimonios, datos y noticias. Alcoy. 1977, volumen i, pảg. 443.

8.- J.A. Ramos Vidal: Demografia. economia y socredad en la comarca del Bajo Segura durante el sigio XVIII. Orihuela, 1980, pág. 15.

9.- J. Tena Meliá: La Blanca Paloma de Altura. Valencia, 1984, pág. 50; citada por A. Ariño Villarroya: Temes d'etnografía valenciana. V'ol.IV. Festes, rituals i creences. IVEI. València, 1988, pág. 291, nota 274

10.- Las referencias bibliográficas a la devoción por la Santa Faz en Alicante son muy numerosas, en la mayoría de los casos teñidas de gran religiosidad y misticismo. Para una interpretación reciente y desapasionada acerca de la historia de la reliquia ver E. Giménez. López: "La Santa Faz y Alicante: peregrinaje por cinco siglos de fe", en Santa Faz. V Centenario. Ayuntamiento de Alicante. Alicante, 1988, pp. 33-39. Asimismo E. Cutillas Bernal: El patronato de la ciudad de Alicante sobre el monasterio de la Santa Verónica en la huerta de la ciudad, Tesis Doctoral inédita, Facultad de Filosofía y Letras, Universidad de Alicante, 1995. Para encontrar las reterencias mas antiguas conviene recurrir a ios cronistas: Bendicho, V.: Chronica de la muty ilustre, noble y leal ciudad de Alicante. Alicante, 1640. Manuscrito conservado en el Archivo Municipal de Alicante. De esta cronica existe una edición transcrita y anotada por $\mathrm{M}^{\mathrm{a}}$ Luisa Cabanes Catala, publicađa por el Ayuntamiento de Alicante en 1991, pudiéndiose encontrar datos relativos a la cuestion en Ia Parte Primera. Libro Primero, capitulos 28 al 30. Los jesuias J.B. Maltés y L. López, en su ya citada Historia de Alicante de mediados del siglo XVIII, siguen fielmente a Bendicho cuando se refieren a la reliquia de la Santa Faz en los capítulos VIII al XII de la Década IV. [: cronista decimonónico Rafael Viravens Pastor también dedica especial atención al tema: Crónca de la muy ihustre y siempre fiel ciudad de Alicante. Imprenta de Carratalá y Gadea. Alicante, 1876, pp. 69-93. De esta crónica hay dos facsimiles, uno editado en 1976 por A. Soler Llorca y otro, en el año 1989, gracias a la colaboración del Ayuntamiento de la ciudad y el Banco de Alicante.

11.- Archivo Municipal de Alicante (AMA). Cabildos, armario 9, libro 15. fols. 5 y 17: cabildos de 8-I1725 y de $26-1-1725$.

12.- AMA. Cabildos, armario 9, libro 16, fol. 16.

13.- Los naturales del lugar bautizaron a 1728 como el "año del diluvio", cifr. en I. Font Tullor: Historia del clima de España, pág. 102.

14.- "Las riadas desde el año 1535 hasta la de Santa Teresa en 1879", en Revista Oleza, Orihuela, 199!, sin paginar.

15.- J.A. Ramos Vidal: Demografia, economia y sociedad, pág. 15.

16.- V. Boix y Ricante: Historia de la ciudad y reino de Valencia, Valencia, 1845. J.B. Perales: Décadas de la historia de la insigne y coronada ciudad y reino de Valencia. Continuación de las Décadas que escribió el licenciado y rector Gaspar Escolano. Terraza, Aliena y Compañía Editores. Valencia-Madrid. 1880, Libro IV, capitulo VII, pp. 916-917.

17.- Archivo General de Simancas (AGS). Secretaría y Superintendencia de Hacienda, legajo 576, Ei lugar de Torrent en el reyno de Valencia, s.f. 
18.- J.B. Perales: ob. cit., libro IV, capítulo VII, pág. 917.

19.- AMA. Cabildos, armario 9, libro 20, fol. 46v (Cabifdo de 4-3-1730); libro 27, fol. 9 (Cabildo de 1-21737), fol. 44 (Cabildo de 6-4-1737), fol. 46 (Cabildo de 8-4-1737); Libro 33, fol. 29 (Cabildo de 9-31739).

20.- J.A. Ramos Vidal: Demografia, economia y sociedad, pág. 16.

21.- "L.as riadas, desde el año 1535 ...".

22.- J.A. Ramos Vidal: Ibidem, pág. 16.

23.- AMA. Cabilios, armario 9, libro 27, ff. 9,44 y 46, correspondientes a los cabildos ceiebradios los dias uno de febrero y 6 y ocho de abril de ese año 1737. En Orihuela el cabildo ciudadiano acordó celebrar una procesión para demandar lluvias el 26 de abril; J.A. Ramos Vidal: Demografikr, economia y sociedad, pág. 16 .

24.- J.A. Ramos Vidal: Ibidem, pág. 16.

25.- Archivo Municipal de Orihuela. Copia de la información fecha por el Caballero Sindico Procurador Gral. de esta ciudad sobre los daños y perjuicios padecidos en esta población, y su huerta con los temporales de llubias y avenidas de este rio Segura y Ramblas (...). Legajo $38, n^{\circ} 2$.

26.- "Se han perdido quasi universalmente todas las simenteras que se habían hecho en las tierras de este resinto, se han arrancado y destruido muchos arboles fructiferos de morerales, olivares y ouros importantes y utiles, se han arrancado y robado muchas porciones de tierras panificables y bien cultibadas quedando quasi incultas, se han enrrunado y segado con las porciones de tarquines y piedra que ha traido la inundación (...) se han muerto y perdido muchas cabailerỉas de iabranza (...) y muchos ganados de todas especies e innumerables porciones de frutos existentes persividos y conservados en los graneros y bodegas. como de trigo, sevada, panizo, lino, garvanzos, aceite, vino y otros especiosos esquimos (...)". Ibidem, if. $1-2$.

27.- J.A. Ramos Vidal: Demografía, economía, pág.16.

28.- A. Alberola Romá: "Agricultores y monopolistas: el control del agua de riego en las comarcas meridionales del País Valenciano durante la Edad Moderna", en $\mathrm{M}^{\mathrm{a}} \mathrm{T}$. Pérez Picazo y G. Lemeunier: Agua y modo de producción, Barcelona, 1990, pp. 188-211. A. Alberola Romá: El pantano de Tibi y el sistema de riegos en la Huerta de Alicante, Fundación Cultural CAM-Instituto de Cultura "Juan Gil-Albert", Alicante, 1994 ( $2^{2}$ edición), pp. 166 y ss.

29.- AMA. Cabildos, armario 9, libro 41 , fol. $42 \mathrm{v}$.

30.- El jesuita Lorenzo López, en su crónica sobre la ciudad de Alicante, se refiere al crưo e inhabiual invierno que padeció la ciudad así como a la sorprendente nevada del dia 15 de enero del año 1752. Cifr. en J.B. Maltés y L. López: lice ilustrada. Historia de la muy noble leal y fidelisima ciudad de Alicante, pp. $457 \mathrm{v}-458$. Referencias a este hecho se hallan también en R. Viravens Pastor: Crónica de la muy ilustre y siempre fiel ciudiad de Alicante, pág. 319. En torno al remunerador comercio de la nieve en la ciudad de Alicante ver J. Mallol Ferrándiz: Alicante y el comercio de la nieve en la eciad moderna. Universidad de Alicante. Alicante, 1990.

31.- E. Giménez López: Alicante en el siglo XVIII. Economía de una citudad portuaria del Antiguo Régimen. Valencia, 1981, pág. 274. A. Alberola Romá: Jurisdicción y propiedad de la tierra en Alicante (siglos XVII y XVIII), Universidad-Ayuntamiento, Alicante, 1984, pp. 259 y ss. 
32.- J.M. Palop Ramos: Hambre y lucha antifeudal, pp. 91-92. E. Giménez López: Alicante en el siglo XVIII, pp. 275-278.

33- AGS. Secretaria y Superintendencia de Hacienda, legajo 577, Los alcaldes y regidores del lugar de Soneja y Baronia de Asuebar, 1757.

34.- ACS. Secretaria y Superintendencia de Hacienda, legajo 577, D. Pedro Rebollar al conde de Valparaíso. Madrid. 25-10-1757.

35.- AGS. Secretaria y Superintendencia de Hacienda, legajo 577, El consejo, justicia y regimiento del lugar de Argelita, sin fecha.

36.- AGS. Secretaria y Superintendencia de Hacienda, legajo 577, Informe de Pablo Ivañes, escribano real y publico en el reyno de Valencia. Argelita, 11-10-1756.

37.- AGS. Secretaria y Superintendencia de Hacienda, legajo 577, D. Pedro Rebollar al conde de Valparaiso. Madrid, 17-11-1756.

38.- J.A. Ramos Vidal: Demografia. economia, pág. 17.

39.- AGS. Secretaria y Superintendencia de Hacienda, legajo 577, La villa de Aspe del Reino de Valencia puesta a los pies de V.M. 5-4-1758.

40.- Uno de los testigos que figuran en la relación declaraba que "es notoria la esterilidad y falta de llivias que en tiempo del simentero y demas succesivo hasta el presente mes en estos paisses y en el de la villa de Aspe: que los vessinos de esta (...) sembraron mucho de la especie de trigo y sevada anis y cominos al parecer sin la suficiente sason y con la esperanza de que naseria si en adelante llovia. Que por falta de aguas el sembrado que ha nasido podra producir la simiente que su dueño expendio, bien entendido que los de esta calidad, que es la mejor, no alcanzara a la quarta parte y esta podra producir la simiente si el tiempo le acude; que la cosecha de granos en Aspe (...) es una de ls mas principales para su subsistencia, que la otra de vino tambien principal en el presente año considera por su inteligencia que por el daño que trae de la langosta en los passados y de sequía en el presente haran bastante de mantenerse las plantas, y que estas podran producir la mitad o menos del fruto que devieran si el tiempo les acude (...)"; AGS. Ibidem. Relación de testigos, 25-4-1758.

41.- AMA. Cabildos, armario 9, libro 49, fol. 267.

42.- AGS. Secretaria y Superintendencia de Hacienda, legajo 578, D. José de Avilés al conde de Valparaíso. Valencia, 25-1-1759. El Intendente manifestaba textualmente en su informe que la población, en razón del lugar en el que se asentaba, "está muy expuesta a avenidas y tempestades que ciestriven su término y frutos con frecuencia". 